\title{
Pelatihan Penggunaan Aplikasi Pengolah Data Microsoft Excel untuk Meningkatkan Kinerja Guru di MI Muhammadiyah Gandatapa
}

\author{
Training on the Use of Microsoft Excel Data Processing Applications to Improve \\ Teacher Performance at MI Muhammadiyah Gandatapa. \\ Lahan Adi Purwanto ${ }^{1 *}$, Achmad Fauzan ${ }^{2}$, Abid Yanuar Badharudin ${ }^{3}$ \\ ${ }^{1,2,3)}$ Program Studi Teknik Informatika, Fakultas Teknik dan Sains, Universitas Muhammadiyah Purwokerto \\ J. Raya Dukuh Waluh, Kembaran 53182, Indonesia. \\ email: ${ }^{* 1}$ lahanadipurwanto@ump.ac.id
}

\begin{abstract}
ABSTRAK
Kegiatan Pengabdian ini bertujuan untuk memberikan pelatihan kepada Guru MI Muhammadiyah Gandatapa tentang penggunaan aplikasi pengolah data Microsoft Office Excel. Penyelenggaraan pelatihan dimaksudkan untuk meningkatkan produktivitas Guru dalam rangka menyongsong dan ikut berperan dalam kancah perkembangan teknologi informasi. Metode pelaksanaan pada pelatihan ini menggunakan metode ceramah, demonstrasi, tanya jawab (diskusi), dan praktik langsung di laboratorium komputer. Materi yang disampaikan mulai dari pengenalan secara umum, pengenalan menu dan tools, hingga contoh penyelesaian masalah pengolahan data pada Microsoft Office Excel. Pada akhir kegiatan dilakukan evaluasi dengan cara memberikan studi kasus untuk mengetahui kemampuan peserta dalam memahami dan mempraktekkan materi yang telah disampaikan. Kegiatan ini dilaksanakan di Laboratorium Komputer Program Studi Teknik Informatika, Fakultas Teknik dan Sains, Universitas Muhammadiyah Purwokerto. Durasi pelatihan dilaksanakan selama 8 (delapan) jam. Peserta yang mengikuti pelatihan mencapai $80 \%$ dari yang telah ditargetkan. Pengisi pelatihan terdiri dari tim pelaksana pengabdian yang terdiri dari 3 (tiga) orang dan dibantu 1 (satu) orang mahasiswa sebagai astisten. Peserta merasakan manfaat dari pelatihan ini. Selain itu, seluruh peserta memberikan kesan yang baik terhadap pelaksanaan pelatihan ini dan menyarankan diadakan pelatihan-pelatihan yang berhubungan dengan teknologi informasi secara rutin diwaktu mendatang.
\end{abstract}

Kata Kunci: teknologi, excel, data

\section{ABSTRACT}

This service activity aims to provide training to MI Muhammadiyah Gandatapa Teachers on the use of the Microsoft Office Excel data processing application. The training is intended to increase teacher productivity in the context of welcoming and playing a role in the development of information technology. The method of implementation in this training uses lectures, demonstrations, question and answer (discussion) methods, and direct practice in a computer laboratory. The material presented started from general introduction, introduction to menu and tools, to examples of solving data processing problems in Microsoft Office Excel. At the end of the activity, an evaluation was carried out by providing a case study to determine the ability of the participants to understand and practice the material that was presented. This activity was carried out at the Computer Laboratory of the Informatics Engineering Study Program, Faculty of Engineering and Science, Muhammadiyah University of Purwokerto. The training duration is carried out for 8 (eight) hours. Participants who took part in the training reached $80 \%$ of the target. The training participants consist of a community service team consisting of 3 (three) people and assisted by 1 (one) student as assistant. Participants felt the benefits 
of this training. In addition, all participants gave a good impression on the implementation of this training and suggested that trainings related to information technology be held regularly in the future.

Keywords: technology, excel, data.

\section{Pendahuluan}

Madrasah Ibtidaiyah Muhammadiyah (MIM) Gandatapa merupakan sebuah Amal Usaha Muhammadiyah (AUM) yang menyelenggarakan pendidikan pada jenjang pendidikan dasar setara dengan Sekolah Dasar. MIM Gandatapa beralamat di Jalan Baturraden Timur RT 06 RW 02 Desa Gandatapa, Kecamatan Sumbang, Kabupaten Banyumas, Jawa Tengah 53183. MIM Gandatapa didirikan oleh Pimpinan Ranting Muhammadiyah Gandatapa yang diselenggarakan oleh Majelis Pendidikan Dasar dan Menengah (Dikdasmen) Pimpinan Cabang Muhammadiyah Sumbang. Sesuai dengan Pedoman Pimpinan Pusat Muhammadiyah Nomor 01/Ped/I.0/B/2018 Tentang Pendidikan Dasar Dan Menengah Muhammadiyah Bab II Pasal 5, pendidikan dasar dan menengah Muhammadiyah bertujuan:

a. Berkembangnya potensi siswa agar menjadi manusia yang beriman dan bertakwa kepada Allah SWT, berakhlak mulia, sehat, berilmu, cakap, kreatif, mandiri, berkemajuan dan unggul, menjadi warga negara yang demokratis dan bertanggung jawab.

b. Berkembangnya potensi santri menjadi ulama, pemimpin/zuama, dan pendidik dalam membangun peradaban.

Keadaan MIM Gandatapa dalam menuju tujuan pendidikan juga sesuai dengan PP Nomor: 17 Tahun 2010 tentang Pengelolaan dan Penyelenggaraan Pendidikan, serta melaksanakan Undang-undang No. 20 Tahun 2003 tentang Sistem Pendidikan Nasional yang bertujuan sebagai berikut: "Pendidikan Nasional bertujuan untuk berkembangnya peserta didik agar menjadi manusia yang beriman dan bertakwa kepada Tuhan Yang Maha Esa, berakhlak mulia, sehat, berilmu, cakap, kreatif, mandiri, dan menjadi warga negara yang demokratis serta bertanggung jawab".

MIM Gandatapa mulai meyelenggarakan proses Kegiatan Belajar Mengajar (KBM) pada tahun 2013. Personil dari MIM Gandatapa terdiri dari Kepala Madrasah, 7 (tujuh) guru kelas, 1 (satu) guru Pendidikan Agama Islam (PAI), dan 1 (satu) bagian administrasi. Dalam menyelenggarakan proses Kegiatan Belajar Mengajar (KBM), MIM Gandatapa menerapkan kurikulum Kementerian Agama dan Departemen Pendidikan Nasional yang berlaku saat ini, yaitu Kurikulum Tingkat Satuan Pendidikan (KTSP) untuk mata pelajaran umum dan Kurikulum K-13 untuk mata pelajaran Agama. Walaupun masih terbilang cukup muda usianya dan belum meluluskan siswanya (baru akan meluluskan siswanya pada tahun pelajaran 2018/2019), MIM Gandatapa telah berhasil mendapatkan Akreditasi B pada bulan Oktober 2018. Hal ini menjadi bukti bahwa MIM Gandatapa tidak memandang remeh dalam hal penyelenggaraan pendidikan. Selain itu, grafik penerimaan siswa baru juga menunjukkan tren yang positif. Terbukti mulai tahun ajaran ini (2018/2019), MIM Gandatapa menerima siswa kelas 1 (satu) sebanyak 2 (dua) kelas, sedangkan angka penerimaan siswa pada sekolah setingkat pendidikan dasar di daerah sekitar MIM Gandatapa mengalami penurunan.

Seiring dengan bertambahnya jumlah siswa, MIM Gandatapa selalu berupaya mengembangkan Sumber Daya Manusianya guna meningkatkan kualitas pelayanan dalam penyelenggaraan pendidikan. Pada pelaksanaannya, yakni penggunaan kurikulum K-13, guru dituntut untuk lebih banyak memanfaatkan aplikasi komputer dalam penyelenggaraan pendidikan, misalnya dalam pembuatan RPS/RPP, silabus, rekapitulasi nilia siswa, dll. Namun, berdasarkan wawancara awal terhadap guru MI Muhammadiyah Gandatapa, kemampuan guru terhadap penggunaan aplikasi komputer, khususnya aplikasi pengolah data Microsoft Office Excel masih kurang. Microsoft Office Excel merupakan program untuk mengolah data secara otomatisyang meliputi perhitungan dasar, penggunaan fungsi-fungsi, 
pengolahan data, pembuatan grafik, dan manajemen data (Jarot, dkk, 2012). Salah satu cara untuk meningkatkan kemampuan dalam penggunaan aplikasi komputer, khususnya Microsoft Office Excel, adalah dengan memberikan pelatihan penggunaan perangkat lunak Microsoft Office Excel bagi guruguru MI Muhammadiyah Gandatapa.

\section{Metode}

Pendidikan dan pelatihan ini menggunakan metode ceramah, demonstrasi, tanya jawab (diskusi), dan praktik langsung di laboratorium komputer. Adapun teknik pelaksanaan kegiatan ini menggunakan langkahlangkah sebagai berikut:

a. Pengenalan secara umum tentang perangkat lunak Microsoft Office Excel 2013.

b. Pengenalan menu dan tools Microsoft Office Excel 2013 beserta cara penggunaannya.

c. Demonstrasi dan praktik langsung bagaimana cara menggunakan Microsoft Office Excel 2013 untuk menyelesaikan permasalahan pengolahan data dengan mengambil beberapa contoh permasalahan.

d. Evaluasi yang bertujuan untuk mengetahui kemampuan peserta dalam memahami dan mempraktekkan materi yang telah disampaikan.

Evaluasi kegiatan dilakukan diakhir kegiatan pelatihan dengan mempersilahkan peserta pelatihan untuk menyelesaikan permasalahan yang berkaitan dengan pengolahan data dengan menggunakan fitur-fitur yang terdapat pada Microsoft Office Excel 2013 yang telah dipelajari diawal. Contoh permasalahan mengambil contoh permasalahan pengolahan data yang terdapat di sekolah, seperti pengolahan data nilai. Hal ini dimaksudkan untuk mengetahui sejauh mana penguasaan materi pelatihan. Sedangkan indikator dan tolak ukur yang digunakan untuk menyatakan keberhasilan kegiatan pelatihan ini adalah jika tingkat pemahaman peserta pelatihan mencapai minimal $60 \%$. Hal ini diukur dari jumlah peserta pelatihan yang tadinya tidak bisa menggunakan fasilitas-fasilitas Microsoft Office Excel 2013 dengan baik untuk mengolah data menjadi bisa.

\section{Hasil dan Pembahasan}

Kegiatan pelatihan ini dilaksanakan di Laboratorium Komputer Program Studi Teknik Informatika, Fakultas Teknik dan Sains, Universitas Muhammadiyah Purwokerto yang beralamat di Gedung Fakultas Teknik dan Sains, Kampus I Universitas Muhammadiyah Purwokerto pada hari Ahad, 24 Februari 2019 mulai pukul 08.00 s.d. 16.00 yang diikuti oleh 8 orang peserta (daftar hadir terlampir). Target yang ditetapkan dalam pelatihan ini adalah 10 orang, sehingga target telah tercapai (80\%) (terdapat dua peserta berhalangan hadir). Hal ini menandakan antusiasnya para guru dalam menyikapi dan merespon kegiatan ini. Selain itu, guru juga sudah mulai tersadar betapa pentingnya untuk meningkatkan kinerjanya. Selama pelatihan, peserta mendapatkan fasilitas makalah materi beserta tutor/instruktur dan asisten, snack, makan siang, dan sertifikat. Instruktur terdiri dari ketua pelaksana kegiatan (Lahan Adi Purwanto, S.Kom., M.Kom.), anggota pelaksana kegiatan (Achmad Fauzan, S.Kom., M.Cs. dan Abid Yanuar Badharudin, S.Kom., M.Kom.). Selain itu dibantu oleh satu orang mahasiswa sebagai asisten yaitu Ade Gilang Hendra Irianto. Instruktur dan asisten dilibatkan dengan maksud agar kegiatan pelatihan ini mempunyai dampak yang benarbenar dapat dirasakan oleh peserta karena kesulitan-kesulitan peserta saat mengikuti pelatihan dapat teratasi dan peserta mendapatkan bimbingan yang optimal. Foto kegiatan pelatihan ditunjukkan pada Gambar 1. 


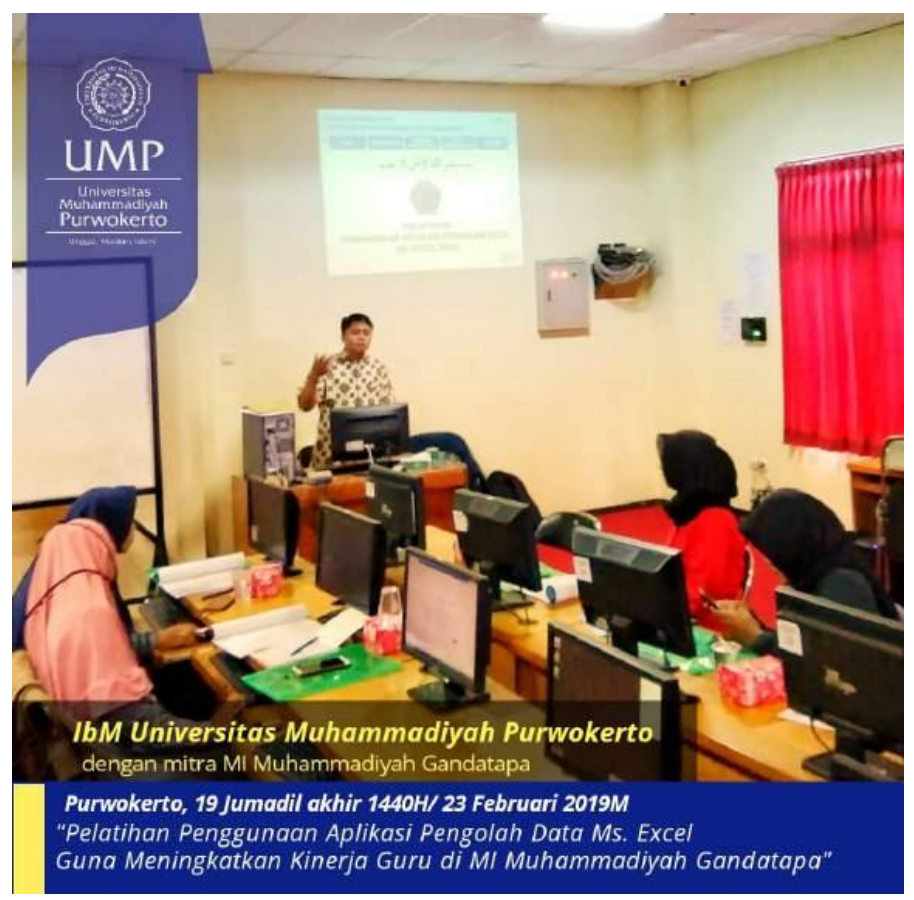

Gambar 1. Kegiatan Pelatihan Penggunaan Aplikasi Microsoft Office Excel.

Sebagai acuan berhasil tidaknya kegiatan pelatihan, dilakukan evaluasi terhadap materi yang diberikan. Setelah dilaksanakan pelatihan diperoleh hasil bahwa $60 \%$ dari peserta yang belum pernah menggunakan sebagian besar fasilitas-fasilitas Microsoft Office Excel 2013 yang diberikan, 30\% dari peserta yang belum pernah melakukan pengolahan data nilai dengan menggunakan Microsoft Office Excel 2013, dan 100\% peserta mengenal perangkat lunak Microsoft Office Excel 2013 tetapi belum memaksimalkan fitur-fitur yang terdapat di dalamnya. Setelah diadakannya pelatihan ini peserta dapat menggunakan fasilitas-fasilitas Microsoft Office Excel 2013 yang diberikan pada saat pelatihan. Bahkan $100 \%$ peserta merasakan manfaat dari pelatihan ini dan berkeinginan untuk memanfaatkan materi yang telah didapatkan untuk meningkatkan kinerjanya, khususnya dalam menyelesaikan permasalahan pengolahan data di sekolahnya. Selain itu, seluruh peserta memberikan kesan baik terhadap pelaksanaan pelatihan ini dan menyarankan diadakan pelatihan-pelatihan yang berhubungan dengan teknologi informasi secara rutin diwaktu mendatang.

\section{Kesimpulan}

Berdasarkan hasil evaluasi yang dilakukan, maka dapat disimpulkan bahwa:

a. Kegiatan pelatihan penggunaan aplikasi pengolah data Microsoft Office Excel 2013 diterima oleh para peserta pelatihan dengan menunjukkan hasil yang positif.

b. Pelatihan penggunaan aplikasi pengolah data Microsoft Office Excel 2013 mendapat respon yang positif dari para peserta, yang dibuktikan dengan bertambahnya wawasan dan pengetahuan dibandingkan dengan sebelum mengikuti pelatihan. 


\section{DAFTAR PUSTAKA}

Jarot, S. (2012). Buku Pintar Microsoft Office Word-Excel-PowerPoint. MediaKita: Jakarta.

Majelis Pendidikan Dasar dan Menengah. (2018). Pedoman Nomor 01/Ped/I.0/B/2018 Tentang Pendidikan Dasar Dan Menengah Muhammadiyah. Pimpinan Pusat Muhammadiyah. Jakarta.

Republik Indonesia. (2003). Undang-Undang No. 20 Tahun 2003 tentang Sistem Pendidikan Nasional. Lembaran Negara RI Tahun 2003, No. 78. Sekretariat Negara. Jakarta.

Republik Indonesia. (2010). Peraturan Pemerintah No. 17 Tahun 2010 tentang Pengelolaan Penyelenggaraan Pendidikan. Lembaran Negara RI Tahun 2010, No. 23. Menkumham. Jakarta. 